\title{
Mediación con personas con discapacidad: igualdad de oportunidades y accesibilidad de la justicia
}

\author{
M. Pilar MUNUERA GÓMEZ \\ Universidad Complutense de Madrid \\ pmunuera@trs.ucm.es
}

Recibido: 04/06/2012

Aceptado: 13/11/2012

\section{Resumen}

Presentamos las posibilidades que ofrece la mediación a la hora de resolver las situaciones conflictivas que viven las personas con discapacidad y sus familias. Es necesario crear un espíritu de cooperación para transformar la frustración y el dolor de las personas con discapacidad y sus familias en satisfacción, desde el reconocimiento de sus derechos con el fin de aumentar su participación social y su accesibilidad en la toma de decisiones.

La base teórica de la mediación es la negociación, su éxito está inmerso en el proceso de mediar y en el perfil del mediador que genera acuerdos entre las partes en disputa, con el objetivo de lograr que las partes satisfagan sus intereses, creando una nueva relación para el futuro.

Palabras clave: mediación, discapacidad, derechos, conflictos, relación futura.

\section{Mediation with special needs people: equal opportunities and access to justice}

\begin{abstract}
We introduce the possibilities that mediation offers when resolving the conflictive situations that people with special needs and their families live. It is necessary to create a cooperative spirit in order to transform into satisfaction the frustration and sorrow that people with special needs and their families experience, from the acknowledgement of their rights with the purpose to increase their participation in the society and their access to the decision-making.

The theoretical root of mediation is negotiation, its success is intertwined in the process of mediation and in the profile of the mediator which helps the generation of agreement between the parties in dispute, with the objective to obtain the satisfaction of the interests of all the parties involved, creating a new relationship for the future.
\end{abstract}

Keywords: mediation, special needs, rights, conflicts, future relation

\section{Referencia normalizada}

Munuera, P. (2013). "Mediación con personas con discapacidad: igualdad de oportunidades y accesibilidad de la justicia”. Política y Sociedad, Vol.50 núm. 1: páginas. 163-178 
Sumario: 1.Historia de las personas con discapacidad: punto de partida para un cambio. 2.Encuadre jurídico de los derechos de las personas con discapacidad. 3.¿Qué significado tiene el concepto de discapacidad?. 4.Necesidad de una nueva realidad: investigación emancipadora. 5.Sistema Arbitral: garantía de la igualdad de oportunidades, no discriminación y accesibilidad por razón de discapacidad. 6.Mediación y personas con discapacidad. 7.Conclusiones

\section{Historia de las personas con discapacidad: punto de partida para un cambio}

Los cambios producidos en la sociedad en el tratamiento de las personas con discapacidad ha sido fruto de la lucha de las organizaciones sociales formadas por las propias personas afectadas y sus familiares, logrando derechos civiles para su equiparación social desde el énfasis en la supresión de "las barreras del entorno y en su capacidad para asumir en plenitud de derechos un papel dentro de la sociedad como tal, se ha definido el objetivo en función de un logro: la autonomía personal ("independent living")” (Puig de Bellacasa, 1998: 53). Hasta llegar a la situación actual se ha recorrido un camino de sufrimiento, discriminación e exclusión social.

La historia de las personas con discapacidad pone de manifiesto las dificultades de ser considerados ciudadanos con los mismos derechos que el resto de la población. Las dificultades de acceder a la comprensión de los términos judiciales y administrativos permiten visualizar la necesidad de contemplar su protagonismo en la consideración de ciudadanos, así como la gestión pacifica de los conflictos en su vida cotidiana facilitando con ello su inclusión social. Se debe favorecer el respecto profundo a la capacidad que tienen las personas con discapacidad a tomar sus decisiones y poder equivocarse como cualquier ciudadano, miembro de una sociedad que respeta sus derechos, favoreciendo la igualdad y la equidad facilita la accesibilidad a la educación, al trabajo y a la justicia.

El movimiento asociativo de las personas con discapacidad y sus familiares han favorecido la unión de personas que viven los mismos problemas iniciando un proceso de cambio en la sociedad, gracias a "la lucha de los discapacitados de Estados Unidos por una vida independiente y por los derechos civiles empezó a producir su efecto. El estudio de estas luchas colectivas resultaba más fácil dentro de la sociología del conflicto que acababa de surgir. Estos esfuerzos por alcanzar una vida independiente (DE JONG, 1979) mediante el fin de la discriminación y la inclusión de sus derechos en la sociedad ha conducido al surgimiento de la perspectiva "sociopolítica" de la sociología estadounidense. Como ocurrió en el Reino Unido, a la cabeza de estas ideas han estado los propios discapacitados, como HAHN (1988) y ZOLA (1979)" (Oliver, 1998: 39).

Desde distintas instituciones se lucha por el reconocimiento de los derechos recogidos en la Convención Internacional sobre los Derechos de la Personas con Discapacidad (CIDPD) de 2006. Estos derechos conectan directamente con el 
reconocimiento de la dignidad humana, desde la autonomía e independencia que toda persona tiene, legitimando la libertad para tomar sus propias decisiones, a la vez que se reconoce su igualdad ante la ley, sin ningún tipo de discriminación. Se espera que por fin la Convención consiga las respuestas adecuadas por parte de la sociedad actual para pasar de una formulación de principios a una práctica de estos nuevos derechos sociales.

A continuación se analizan aspectos jurídicos y sociales para un examen histórico-crítico de las ideas y actitudes que a lo largo de estos siglos han modelado las vidas de las personas con discapacidad determinando su situación actual.

\section{Encuadre jurídico de los derechos de las personas con discapacidad}

"El tratamiento y la consideración de las personas con discapacidad han variado en los últimos tiempos, pues se han superado muchos obstáculos en el proceso de normalización e incorporación de las personas con discapacidad a una vida social plena” (Lorenzo, 2007: 50). En España las primeras medidas específicas se inician a finales de la década de los 60 , con la creación de organismos que velan por los intereses de las personas con discapacidad. Organismos que han ido cambiado adaptándose a la configuración de la discapacidad pasando del «Servicio Social de Asistencia a Subnormales» en 1970 al actual «Instituto de Migraciones y Servicios Sociales» (IMSERSO ) en noviembre de 1997, a la vez que se crea el Comité Español de Representantes de Personas con Discapacidad ${ }^{1}$ (CERMI).

En el Derecho Europeo se encuentra el Tratado de Ámsterdam que contiene la disposición sobre la lucha contra la discriminación en diversos ámbitos, entre los que se encuentra las discapacidades. Siendo la Carta de Derechos Fundamentales de la Unión Europea y el Tratado de Niza, donde se prohíbe la discriminación y a la vez se reconoce el derecho de las personas con discapacidad a beneficiarse de medidas que permitan su integración social. En el ámbito del derecho derivado de la Unión Europea "los principios que impregnaron este movimiento se registraron en la crucial Directiva 2000/78/CE, de 27 de noviembre de 2000, relativa al establecimiento de un marco general para la igualdad de trato en el empleo y la ocupación, acompañada por la Directiva 2000/43/CE del Consejo, de 29 de junio de 2000, relativa a la aplicación del principio de igualdad de trato de las personas independientemente de su origen racial o étnico” (De Lorenzo, 2007: 242-243).

\footnotetext{
${ }^{1}$ Plataforma de representación, defensa y acción de la ciudadanía española con discapacidad que vela por el cumplimiento de los derechos reconocidos en la Convención Internacional (CIDPD), con el fin de alcanzar la ciudadanía plena en igualdad de derechos y oportunidades que el resto de los componentes de la sociedad. Representa a los 3.8 millones de personas con discapacidad que hay en España, significando un $10 \%$ de la población total y más de 7.000 asociaciones que luchan por sus derechos.
} 
La Constitución española de 1978 aborda el tratamiento de las personas con discapacidad considerándolas como titulares de los mismos derechos fundamentales reconocidos a todas las personas, reconoce la igualdad ante la ley, sin que pueda prevalecer discriminación alguna como indica el artículo 14. Indicando que como miembros de un colectivo que requiere una especial protección (artículo 9.2), corresponde a los poderes públicos promover las condiciones para que la libertad y la igualdad de las personas sean reales y efectivas, removiendo los obstáculos que impidan o dificulten su plenitud y facilitando su participación en la vida política, cultural y social. En el artículo 10, sobre los derechos y deberes fundamentales, establece la dignidad de la persona como fundamento del orden político y de la paz social. Todo ello en consonancia con el artículo 49, cuando ordena a los poderes públicos que presten la atención especializada que requieran y el amparo especial para el disfrute de sus derechos. Estos enunciados constituyen hoy uno de los ejes esenciales en la actuación sobre la discapacidad.

Los poderes públicos deben asegurar que las personas con discapacidad puedan disfrutar del conjunto de todos los derechos humanos: civiles, sociales, económicos y culturales. "En países como Dinamarca, Finlandia, Irlanda, Países Bajos, y Suecia, la protección de las situaciones de dependencia es considerada como un derecho universal, asumido por la colectividad y prestado a través de servicios de proximidad" (Asís y Palacios, 2008: 56). Derechos que se han reglamentado en leyes estatales y autonómicas entre las que destacan por su importancia:

1. La Ley de Integración Social de los Minusválidos (LISMI), Ley 13/1982 de 7 de Abril, publicada en el BOE. núm. 103 de 30 de abril de 1982.

2. La Ley de Igualdad de Oportunidades, No Discriminación y Accesibilidad Universal de las Personas con discapacidad (LIONDAU), Ley 51/2003, de 2 de diciembre, publicada en el BOE núm. 289 de 3 de diciembre de 2003 . Ley que tuvo su origen en el desarrollo del derecho de la Unión Europea. Esta ley se justifica por la persistencia en la sociedad de desigualdades y la aparición de nuevos enfoques y estrategias en la manera de entender el fenómeno de la «discapacidad».

Se parte que las desventajas que presenta una persona con discapacidad tienen su origen tanto en sus dificultades personales, pero también y sobre todo en los obstáculos y condiciones limitativas existentes en la propia sociedad, que parte de un patrón de "persona media", no permitiendo desde ese patrón la plena participación de las personas con discapacidad como ciudadanos de pleno derechos. Estos patrones han generado ciudades con grandes barreras arquitectónicas tanto en calles como en edificios (colegios, centros sanitarios, empresas, etc.) traduciéndose en servicios no accesibles y generando grandes barreras de acceso para las personas con discapacidad.

3. Ley 39/2006, de 14 de diciembre, de Promoción de la Autonomía Personal y Atención a las personas en situación de dependencia, (LAPAD) publicada el 15 de diciembre de 2006. En sus motivos está la promoción de la autonomía personal y la atención a las personas en situación de dependencia mediante la creación de un Sistema para la Autonomía y Atención a la De- 
pendencia (SAAD) desde todas las Administraciones Públicas, con el fin de optimizar los recursos públicos y privados. Se reconoce un nuevo un derecho subjetivo, regulado en su artículo 1, donde se garantiza la igualdad en el ejercicio del derecho subjetivo de ciudadanía a la promoción de la autonomía personal y atención a las personas en situación de dependencia, en los términos establecidos en las leyes. En el artículo 2, curiosamente define en primer lugar autonomía, como la capacidad de controlar, afrontar y tomar, por propia iniciativa, decisiones personales acerca de cómo vivir de acuerdo con las normas y preferencias propias así como desarrollar las actividades básicas de la vida diaria. Principios de la ley que se han olvidado, tal vez por la ausencia de medidas prácticas y vinculantes que desarrollen la autonomía, favoreciendo que esta ley sea conocida por la denominación de "ley de dependencia" y se desconozca su objetivo de promoción de la autonomía personal.

4. Ley 26/2011, de 1 de agosto, de adaptación normativa a la Convención Internacional sobre los Derechos de las Personas con Discapacidad. Las personas con discapacidad son reconocidos como sujetos titulares de derechos y no como meros objetos de tratamiento y protección social. Esta ley viene a cerrar el proceso iniciad en 2008 donde España ratifica la Convención y su Protocolo Facultativo. Las demandas y necesidades de las personas con discapacidad serán cubiertas desde la igualdad de oportunidades, desde el respeto a la dignidad inherente a la persona, la autonomía individual (incluida la libertad para tomar las propias decisiones), la independencia de cada ser humano, la no discriminación, la participación e inclusión plenas y efectivas en la sociedad, es decir, desde la aceptación de las personas con discapacidad como manifestación de la diversidad y la condición humana.

Esta ley contempla entre las medidas de defensa de las personas con discapacidad, el arbitraje y otras medidas de carácter judicial, con independencia de la existencia de reconocimiento oficial de la situación de discapacidad o de su transitoriedad, haciendo responsable a las Administraciones públicas de la discriminación que afecte o pueda afectar a las personas con discapacidad $^{2}$.

En materia de discapacidad el marco jurídico garantiza la inclusión social de las personas con discapacidad y abre el camino a la utilización de técnicas de resolución de conflictos como el arbitraje y cómo desde ahí deja abierto un espacio para la utilización de la mediación como otra medida de carácter judicial. "No obstante, la lucha para hacer realidad lo expuesto en los textos jurídicos está aún por desarrollar

\footnotetext{
${ }^{2}$ Esta normativa se encuentra dentro de la Estrategia Española sobre Discapacidad 20122020, que parte de una serie de medidas europeas e internacionales relacionadas con la aplicación de la CIDPD
} 
en España. Es posible que la recuperación de la dignidad intrínseca a través de la bioética dote de nuevos bríos al colectivo de las personas con diversidad funcional, para afrontar esta tarea” (Palacios y Romañach, 2007: 176-177).

\section{3. ¿Qué significado tiene el concepto de discapacidad?}

Es necesario partir de la clarificación de los diferentes términos que hoy se están utilizando en el ámbito de la discapacidad. La CIDPD emplea el concepto de personas con discapacidad generalizando su uso en todas las instancias para detallar "que son aquellas que tienen deficiencias físicas, mentales, intelectuales o sensoriales a largo plazo y que al interactuar con las barreras existentes en la actualidad no pueden realizar su participación plena y efectiva en la sociedad, en igualdad de condiciones con las demás ciudadanos”. Siendo la Convención el primer tratado internacional que regula la importancia de la participación de las personas con discapacidad en la sociedad.

La Ley 26/2011, de 1 de agosto, define la discapacidad como la circunstancia personal en relación con un ecosistema social. Marcando la línea de actuación de una sociedad abierta e inclusiva que debe modificar el entorno social de forma solidaria para acoger a las personas con discapacidad como elementos enriquecedores que ensanchan la humanidad y agregan valor humano, estimando la intervención de todas las personas con capacidades diferenciadas.

En términos jurídicos se considera personas con discapacidad a quienes tienen reconocido un grado de discapacidad igual o superior al 33 por ciento, entrando en esta definición los pensionistas de la Seguridad Social y clases pasivas con una pensión de incapacidad permanente en el grado de total, absoluta o gran invalidez.

Existe una opción diferenciadora más amplia realizada desde el Foro de Vida Independiente en el empleo de la expresión «diversidad funcional», enunciado que fomenta ver a la persona que "se ajusta a una realidad en la que una persona funciona de manera diferente o diversa de la mayoría de la sociedad. Este término considera la diferencia de la persona y la falta de respeto de las mayorías, que en sus procesos constructivos sociales y de entorno, no tienen en cuenta esa diversidad funcional” (Palacios y Romañach, 2007: 108). La utilización de esta terminología lleva implícita la lucha por la inclusión social "que es la lucha por la dignidad en la diversidad y contra la discriminación y la desventaja social, el término fundamental a utilizar es «diversidad funcional», que es el aplicable a todos los ámbitos de la sociedad” (Palacios y Romañach, 2007: 116). Los conceptos utilizados han evolucionado en un breve espacio de tiempo donde "La ideología de la independent living parece tener una inspiración corporativista. En vista de lo anterior, la adopción de un sistema terminológico y conceptual que represente adecuadamente el área de la discapacidad necesita de la crítica y, en su caso, de la reelaboración de las aportaciones disponibles" (Casado, 1998: 37).

Se debe tener en cuenta, que no toda persona con discapacidad se encuentra en una situación de dependencia, "recordando que lo cierto es que la dependencia va 
ligada de un modo u otro a la discapacidad” (Fernández Santiago, 2010: 30). Existen personas con discapacidad que pueden llevar una vida autónoma e independiente, a diferencia de las personas que se encuentran en situación de dependencia que han perdido su autonomía física para realizar las actividades tanto de la vida diaria como de su cuidado personal. La dependencia por tanto engloba dos aspectos: en el primer aspecto, se enmarcan las personas con discapacidades varias (como intelectual, física, sensorial, y psiquiátrica) así como edades muy diversas y no sólo las personas ancianas dependientes; el segundo aspecto incluye elementos clínicos, farmacológicos, sociales, económicos y políticos que tienen profundas implicaciones morales, desde la siguiente clasificación:

1. Dependencia física: Cuando se ha perdido el control de las funciones corporales y la interacción con los elementos físicos del entorno.

2. Dependencia psíquica o mental: Donde se pierde la capacidad de decidir o razonar adecuadamente sobre sus problemas o tomar decisiones ecuánimes sobre su vida.

3. Dependencia sensorial: Se tiene alguna alteración en los sentidos, principalmente en el sentido de la vista y del oído. Esta situación, además de las barreras de accesibilidad de la sociedad ocasionan dificultades en la vida de la persona con dependencia sensorial (en desplazamientos, leer, realizar las tareas domésticas, conducir, trabajar, etc.).

4. Dependencia mixta: Se inicia a partir de una enfermedad, que ocasiona disfuncionalidad de diversa índole, es decir, dependencia física con afectación de la movilidad asociada a problemas sensoriales, con afectación de habla, dificultad de ingesta de alimentos y reducción de comunicación con su entorno.

La discapacidad en la persona no es algo fijo, pues toda persona por el hecho de vivir y envejecer pasa por un proceso de pérdida de capacidad, dándose una situación cambiante que ocasiona limitaciones funcionales de la persona hacia la dependencia creándose la necesidad de apoyos suficientes para resolver sus necesidades. Las limitaciones funcionales (y por tanto la discapacidad de una persona) pueden disminuir notablemente en la medida que la sociedad proporcione recursos para mantener su estatus comunitario y su bienestar personal. Pasos necesarios para elevar la calidad de vida de las personas con discapacidad en la actualidad.

Las personas con discapacidad en su mayoría no tienen las mismas posibilidades que el resto de la ciudadanía, lo que les coloca en una posición de desventaja social muy clara. "Para reducir las desigualdades y la discriminación existente hacia las personas con discapacidad en la estructura social se han de desarrollar políticas sociales transformadoras y no proteccionistas, acciones que traten de modificar la estructura social, mediante medidas de accesibilidad, diseño universal, nodiscriminación y acción afirmativa, que permitan el acceso a los recursos en igualdad de condiciones que el resto de la ciudadanía” (Díaz Velázquez, 2010: 132).

Las personas con discapacidad son personas y piden que sean respetados sus derechos, como consta en el testimonio de Kenneth Iversjö Díaz, que tras sufrir un 
accidente de esquí y tener una lesión medular descubre: "La cuestión estaba enfocada a que yo descubriera quién era realmente, más allá del nombre que mis padres me habían puesto. Tras un buen rato de búsqueda, de repente, se hizo el silencio mental y la respuesta surgió de ese silencio: "¿Quién soy yo? Soy yo, yo mismo». La sensación y la profundidad de este descubrimiento no se puede describir con palabras; lo que se me inspira compartir con ustedes es que con esa experiencia, con esa pregunta, comprendí que yo no era mi cuerpo, tampoco mi mente. Soy ese algo, esa esencia, esa fuente de vida más allá de la materia de carne que es mi cuerpo” (Peñas, 2010: 81).

\section{Necesidad de una nueva realidad: investigación emancipadora}

Las personas con discapacidad fueron apartadas de la sociedad, en algunas ocasiones internadas sin ser reconocida su dignidad como persona sin tener en cuenta su capacidad de decisión. Disposiciones que están llegando a su fin gracias al reconocimiento de sus derechos fruto de la actividad de las organizaciones de este ámbito. Por "carrera moral" GOFFMAN hacía referencia a la serie de interacciones personales mediante las que los individuos estigmatizados adquieren una conciencia de su desprestigiada identidad y de la imagen y expectativas negativas que otras personas tienen de ellos cuando se relacionan (Gerber, 2008: 287). Percepción que les ha llevado a reaccionar contra la marginación, situando el peso de la exclusión social en la persona con discapacidad y no en una sociedad que favorece la discapacidad e imposibilita una atención a las diferencias. Siendo la teoría interaccionista la que "ha explicado la discapacidad como desviación social, y sugiere que la relación entre discapacidad y desviación se puede entender con referencia a la ausencia de obligaciones y responsabilidades sociales que está explícita en el constructo del papel de enfermo y en la visión negativa de la insuficiencia que prevalece en las sociedades industriales y postindustriales” (Oliver, 1998: 37). Proceso que deja atrás diferentes paradigmas de la discapacidad que han favorecido la exclusión de las personas con discapacidad para llegar al actual paradigma de la discapacidad donde la mediación puede ayudar a la promoción de la participación. En el siguiente grafico 1, aparecen representados los paradigmas de la discapacidad (Oliver 1998), relacionados con las diferentes teorías y metodologías que han analizado la realidad de las personas con discapacidad donde aparece la alternativa de mediación para potenciar la participación social con el fin de conseguir el empowerment y el reconocimiento de las personas con discapacidad. 
Tabla 1: Comparativa de Paradigmas y propuesta de mediación, a partir de los criterios de Oliver (1998).

\begin{tabular}{|c|c|c|c|c|}
\hline $\begin{array}{c}\text { Formas de } \\
\text { comprensión }\end{array}$ & Paradigma nuevo & Alternativas 1 (Otros) & $\begin{array}{c}\text { Alternativa 2 } \\
\text { (OLIVER) }\end{array}$ & $\begin{array}{c}\text { Propuesta mediación } \\
\text { Alternativa 3 }\end{array}$ \\
\hline $\begin{array}{c}\text { Teoría } \\
\text { sociológica }\end{array}$ & $\begin{array}{c}\text { (Tragedia personal) } \\
\text { Funcionalismo } \\
\text { Interaccionismo }\end{array}$ & $\begin{array}{c}\text { Sociopolítica Economía } \\
\text { política (pluralista) } \\
\text { Postmodernismo }\end{array}$ & $\begin{array}{c}\text { Economía política } \\
\text { (materialista) }\end{array}$ & $\begin{array}{c}\text { Resolución de } \\
\text { conflictos/mediación }\end{array}$ \\
\hline $\begin{array}{c}\text { Teorización } \\
\text { de alcance } \\
\text { medio }\end{array}$ & $\begin{array}{c}\text { Adaptación/pérdida } \\
\text { Papel del enfermo } \\
\text { Desviación/estigma }\end{array}$ & $\begin{array}{c}\text { Derechos Individuales } \\
\text { Integración Potenciación } \\
\text { personal }\end{array}$ & $\begin{array}{c}\text { Adaptación social } \\
\text { Inclusión Poten- } \\
\text { ciación colectiva }\end{array}$ & Participación social \\
\hline Metodología & $\begin{array}{c}\text { Positivista } \\
\text { Interpretativa }\end{array}$ & $\begin{array}{c}\text { Participativa Investiga- } \\
\text { ción aplicada Investiga- } \\
\text { ción en la acción }\end{array}$ & Emancipadora & $\begin{array}{c}\text { Empowerment } \\
\text { y reconocimiento } \\
\text { social }\end{array}$ \\
\hline
\end{tabular}

Determinados estudios han elogiado la óptica positiva de una sociedad diversa, "podemos observar cómo Safilios-Rothschild, destaca el papel rehabilitador de los propios discapacitados, por los cuales una persona debe aceptarse y aprender a vivir con sus limitaciones, puesto que deben aprender a asumir funciones normales" (Abela, Ortega y Pérez, 2003:84). Es decir, todas las personas tenemos nuestras diferencias y todas podemos llegar a una situación de discapacidad, donde nuestro valor no está ligado a nuestro cuerpo, sino a nuestro valor como personas verificando el valor de las diversas aportaciones que cada persona puede realizar sin tener en cuenta la capacidad o discapacidad de cada cual.

Las personas con discapacidad han vivido bajo paradigmas tradicionales y de rehabilitación que las han marginado socialmente en los últimos siglos.

"A diferencia de los enfoques investigadores tradicionales, los objetivos de la investigación emancipadora en discapacidad garantizan la generación y producción de conocimientos accesibles y significativos sobre las diversas estructuras - económicas, políticas, culturales y ambientales- que originaron y mantienen las múltiples privaciones con que se encuentra una gran parte de las personas con discapacidades y sus familias”(Barnes, 2008: 384).

Se plantea la necesidad de una nueva realidad más accesible, donde sean respetados sus derechos, desde la supresión de las barreras que esta sociedad ha creado. Es "crucial que una teoría de la discapacidad en cuanto opresión se enfrente a esta inferioridad "real” ya que ése es el fundamento sobre el que se basan las teorías que justifican la opresión y, psicológicamente, es un enorme obstáculo al desarrollo de una conciencia política entre las personas con discapacidad” (Abberley, 2008: 35). Para fortalecer la capacidad de tomar decisiones en las personas con discapacidad se debe partir de un análisis sociológico crítico que reflexione "acerca de cómo debería ser la inclusión social del colectivo y proponer y diseñar las políticas sociales que hicieran factible dicha inclusión” (Díaz Velázquez, 2011: 169). 
La idea "de que los problemas de la discapacidad son sociales más que individuales, y de que emanan de la opresión que ejerce la sociedad más que de las limitaciones de los individuos, constituye una parte esencial del proceso de desarrollo de una comprensión adecuada de las respuestas sociales a la discapacidad. Sin embargo, en los esfuerzos por comprender la hegemonía de la discapacidad, es fundamental entender cómo se interconecta la individualización de la discapacidad en los niveles de la sociedad, la política, la práctica y la experiencia personal” (Oliver, 1998: 47). Por todo ello, se deben crear los cauces que permitan la accesibilidad de las personas con discapacidad y garantizar la igualdad de oportunidades desde la administración pública.

\section{Sistema arbitral: garantia de la igualdad de oportunidades, no discrimina- ción y accesibilidad por razón de discapacidad}

La figura del defensor del discapacitado en Suecia (Handikappombudsman) estima la resolución de conflictos o mecanismos de mediación en la asistencia a las víctimas de discriminación. "El Defensor se reúne con las partes, e intenta que lleguen a un acuerdo que implique una compensación económica o cualquier otra solución. El aliciente para llegar a un acuerdo voluntario es la Ley contra Discriminación, que establece posibles sanciones” (Fernández, 2006: 28). En España tenemos experiencias paralelas del defensor/mediador del de las personas con discapacidad que resuelven las denuncias sobre discriminación y accesibilidad.

La Ley 51/2003 de Igualdad de Oportunidades no Discriminación y Accesibilidad Universal de las Personas Discapacitadas, "establece un innovador sistema arbitral que evitará la judicialización de los conflictos y una peculiar regulación en materia probatoria” (Ganzenmüller, 2007: 776). Supone una nueva herramienta para la protección y defensa de las personas con discapacidad, a través del cual se pueden plantear quejas y reclamaciones en materia de igualdad de oportunidades, no discriminación y accesibilidad universal, según el capítulo III, sección $2^{\mathrm{a}}$, artículo 17, como medidas de defensa de las personas con discapacidad, mayores y sus familias, que facilita el arbitraje en los siguientes términos:

1. Previa audiencia de los sectores interesados y de las organizaciones representativas de las personas con discapacidad y sus familias.

2. El sometimiento de las partes al sistema arbitral será voluntario y deberá constar expresamente por escrito.

3. Los órganos de arbitraje estarán integrados por representantes de los sectores interesados, de las organizaciones representativas de las personas con discapacidad y sus familias y de las Administraciones públicas dentro del ámbito de sus competencias.

Este sistema arbitral se desarrolla posteriormente en el Real Decreto 1417/2006, de 1 de diciembre a partir de la normativa comunitaria que orienta a los estados miembros de la Unión Europea en el uso de procedimientos de conciliación complemen- 
tarios a los judiciales y administrativos. Hoy por hoy carece de aplicación y extensión a las comunidades autónomas, sus funciones han sido asimiladas por la Oficina Permanente de la Discapacidad dependiendo del actual Ministerio de Sanidad, Servicios Sociales e Igualdad. Ante este sistema de arbitraje, se presentan las ventajas de la mediación en el ámbito de la discapacidad como medida que facilita el acceso de las personas con discapacidad a la justicia al igual que en otros países.

\section{Mediación y personas con discapacidad}

Leticia García Villaluenga ${ }^{3}$ junto a Ignacio Bolaños, definen en su obra la mediación teniendo en cuenta a las personas con discapacidad, entendiendo "por mediación familiar el sistema cooperativo de gestión y resolución de conflictos entre los miembros de una familia, considerada esta en sentido extenso, que a través de un proceso no jurisdiccional, voluntario, confidencial, facilitado por el mediador, que es un tercero imparcial, neutral, capacitado idóneamente y sin ningún poder de decisión, posibilita la comunicación entre las partes para que traten de plasmar los intereses comunes en un acuerdo viable y estable que resulte satisfactorio para ambas, y atienda, también, a las necesidades del grupo familiar, especialmente las de menores y discapacitados" (Villaluenga, y Bolaños, 2006: 9). Se percibe la capacidad de la mediación siendo "uno de los contextos en los cuales la mediación estamos convencidos que puede ser útil es él de las familias que tienen en su seno alguna persona con disminuciones severas o enfermedades crónica graves” (RipollMillet, 2001: 169), sin llegar a precisar exactamente qué temas se pueden mediar.

La Ley 15/2009, de 22 de julio, de Mediación en el ámbito del derecho privado de la Comunidad de Cataluña, es de las primeras en contemplar la realidad de las personas con discapacidad. Esta ley ve la utilización de la mediación en torno a las familias afectadas por los procesos de discapacidad psíquica o de enfermedades degenerativas que limitan la capacidad de obrar. Aspectos que se desarrollan en su artículo 2. apartado 1., determinando los diferentes conflictos objeto de intervención. Posteriormente de forma más amplia la Ley 1/2009 de 27 de febrero reguladora de la Mediación Familiar en la Comunidad Autónoma de Andalucía, contempla la utilización de la mediación en su artículo 3. d) en los conflictos relativos a la obligación de alimentos entre parientes y los relativos a la atención de personas en situación de dependencia, de acuerdo con la definición introducida por la Ley 39/2006, de 14 de diciembre, de promoción de la autonomía personal y la atención a personas en situación de dependencia.

${ }^{3}$ Directora del Instituto Universitario Complutense de Mediación y gestión de conflictos (IMEDIA). Instituto Universitario de Investigación de la Universidad Complutense de Madrid, aprobado en Consejo de Gobierno de la Universidad Complutense el día 26 de febrero de 2007. 
Estas leyes abren una vía al empleo de la mediación en el ámbito de la discapacidad que puede favorecer un proceso extrajudicial de resolución de conflictos en relación a las necesidades y derechos de las personas con discapacidad. Relación establecida entre la lógica de los derechos, propugnada por los juristas y la lógica de las necesidades de los profesionales de ciencias humanas (Folger y Jones, 1997). Para potenciar la autonomía, es decir, la capacidad de tomar decisiones en las personas con discapacidad y su participación como ciudadanos con plenos derechos. Las propuestas de otros autores están en "utilizar dos campos de debate dialéctico y conceptual: la bioética y el Derecho, con el fin de conseguir la plena dignidad de todo el colectivo y, por extensión, de toda la sociedad“ (Palacios, y Romañach, 2007: 176-177). Se debe valorar los beneficios de la utilización de la mediación en la construcción del empowerment y el reconocimiento de la persona con discapacidad, como la capacidad de la mediación en crear un espacio de diálogo creando una convivencia armónica por la consideración y reconocimiento de los derechos de todas las personas con discapacidad.

El mediador en este contexto deberá cumplir los requisitos fijados en el Reglamento de Mediación Civil y Mercantil que está pendiente de su publicación a la vez que una formación adicional en este ámbito para resolver los siguientes conflictos:

- En procesos de separación y divorcio y conflictos de convivencia permitiendo un espacio de dialogo e información adaptada.

- Discriminación en el empleo por motivo de discapacidad, falta de adaptación funcional para el adecuado desempeño del trabajo, es decir, igualdad de oportunidades con las prestaciones adecuadas.

- Disputas relacionadas con la evaluación y designación del centro de educación pública apropiado para la persona que tiene una discapacidad. Aquellos menores que por motivo de su discapacidad son excluidos en su centro, necesitan una resolución rápida, pues el tiempo de espera de un proceso judicial suele ser de varios cursos, lo que puede dar lugar a la pérdida de su escolarización.

- En procesos de incapacitación, velando por la igualdad de poder entre las partes y permitiendo la participación en la toma de decisiones de la persona con discapacidad de forma adaptada.

- Como alternativa a procesos judiciales de personas con discapacidad que permanecen ingresadas en prisión sin compresión de su falta o por falta de recursos sociales apropiados.

- Conflictos al "tomar decisiones" sobre el tratamiento o elección de prestación asistencial a elegir. Vendría a permitir el fortalecimiento de la capacidad de decisión de la persona con discapacidad (donde estar ingresado, elección de la prestación o recurso social, etc.).

- Conflictos de relación/comunicación entre la persona con discapacidad y sus familiares: salida del núcleo familiar, piso tutelado, etc. En personas con discapacidad jóvenes (decisiones sobre su forma de vivir, horarios, medios de transporte, vacaciones, etc.). En mayores (elección del cuidador 
principal, descanso del cuidador, prestaciones asistenciales alternativas al cuidador principal,...etc.), adaptando a sus circunstancias la información.

- Conflictos de comunicación entre la persona con discapacidad y el profesional (relación laboral, calidad de relación, horario laboral,...). Errores o negligencias de los profesionales que atienden a personas con discapacidad (Mala práctica profesional).

- Con la administración pública en el desacuerdo de la prestación de dependencia asignada por los profesionales de servicios sociales. Tema previsto en la futura ley de servicios sociales de Andalucía.

- En la resolución de conflictos vecinales relacionados con la supresión de barreras arquitectónicas para una adecuada accesibilidad al edificio de la persona con discapacidad. Medidas contempladas en la legislación actual que se encuentran paralizadas.

- En todas aquellas acciones que permitan la accesibilidad de las personas con discapacidad a la participación social de manera plena, esta mediación podría llevarse a través de mediadores institucionales o mediadores ciudadanos (Six 1997).

A nivel internacional existen experiencias donde la mediación es la vía extrajudicial para resolver conflictos relacionados con la discriminación que viven las personas con discapacidad. En primer lugar, la Ley sobre Estadounidenses con Discapacidades, Americans with Disabilities Act (ADA) de 1990, es una ley federal de derechos civiles diseñada para evitar la discriminación social de las personas con discapacidad empleadas. Se facilita a las personas con discapacidad su participación completa en la sociedad a través de la resolución de los conflictos de su entorno laboral. Un principio fundamental de esta ley es la igualdad de oportunidades laborales para aquellas personas con discapacidad que deseen trabajar y estén calificadas para hacerlo, contemplando la mediación como una estrategia que hace más accesible la resolución de los conflictos que se puedan plantear en el medio laboral (Munuera y Rondón 2011). Facilitando con esta práctica el acceso a la justicia de las personas con discapacidad que no tienen que esperar la celebración de un juicio para resolver los conflictos planteados en su entorno laboral. En segundo lugar se sitúa la Ley relativa a Educación del Estado de Nueva York (julio de 1995), donde el Congreso de los EEUU reconoció la necesidad de proporcionar oportunidades adicionales para una resolución rápida de las disputas que se daban en centros de educación especial. Se estableció un período de resolución de 30 días, permitiendo a los padres y a las escuelas trabajar en sus diferencias siempre que un padre presentase una queja según el proceso de mediación establecido en la Agencia de Educación Local (Local Education Agency-LEA). Esta ley facilitó la mediación en los distritos escolares para los padres a fin de mejorar la comunicación y cooperación, resolviendo cuestiones relacionadas con programas y servicios de educación especial. En junio de 1997, se aprobó como la Ley relativa a Educación de Personas con Discapacidades (Individuals with Disabilities Education Act - IDEA). 
La evolución de la mediación en España en los últimos quince años presenta una perspectiva prometedora. Se han ido sentando los cimientos de un verdadero cambio de mentalidad, posibilitando que la mediación sea un nuevo yacimiento de empleo fortaleciendo el valor del dialogo en la sociedad (Munuera 2006).

\section{Conclusiones}

La realidad de las personas con discapacidad ha evolucionado en el reconocimiento de los derechos sociales avance que no viene acompañada con el día a día de las personas con discapacidad. Se plantea la necesidad de un paradigma que potencie la participación social de las personas con discapacidad para conseguir su empowerment y reconocimiento.

La aplicación de la mediación con personas con discapacidad despierta un interés especial como alternativa a la resolución de los conflictos existentes, en un momento histórico donde las instituciones reciben una conflictividad cada vez más alta por la falta de recursos, además de carecer de estrategias propias para solucionar sus conflictos en un espacio no-jurídico (Munuera 2012).

La existencia de un Sistema Arbitral de Quejas y Reclamaciones en Materia de Igualdad de Oportunidades, no Discriminación y Accesibilidad por Razón de Discapacidad, y la figura del Defensor del Discapacitado o mediador de las personas con diversidad funcional en determinadas comunidades autónomas o ciudades, pueden ser los impulsores de la utilización de la mediación en este ámbito con medidas que ayuden a resolver las dificultades o conflictos de accesibilidad en el trabajo, en salud, en educación, etc., implementando su utilización.

La mediación puede ser la alternativa rápida y eficaz para resolver los conflictos que reclaman las personas y sus familias en los tribunales, con el fin de ayudarles en el ejercicio de su derecho a comprender. También puede favorecer la promoción de su autonomía resolviendo conflictos en materia de discriminación social en un espacio de diálogo. El mediador puede resolver los conflictos de comunicación y de relación en el ámbito de la discapacidad para poder aumentar su bienestar social.

A través de la mediación se puede favorecer la construcción de una nueva identidad

“Esta comprensión ha supuesto un punto y aparte en mi vida. Desde entonces, no soy un tetrapléjico, sino que tengo un cuerpo con un estado de tetraplejia. Esto me dio un sentido de libertad sobre la discapacidad mucho más amplio del que pueden imaginar” (Peñas, 2010: 81). 


\section{Referencias bibliográficas}

Abela, J. A., Ortega, J. F. y Pérez, A. M. (2003): "Sociología de la discapacidad. Exclusión e inclusión social de los discapacitados”. Revista del Ministerio de Trabajo y Asuntos Sociales n ${ }^{\circ} 45$, pp. 77-107.

Abberley, P. (2008): "El concepto de opresión y el desarrollo de una teoría social de la discapacidad” en Barton, L. (comp). Superar las barreras de la discapacidad. Madrid: Morata.

Asís, R. de y Palacios, A. (2007): Derechos humanos y situaciones de dependencia. Madrid: Instituto de Derechos Humanos "Bartolomé de las Casas”, Dykinson.

Barnes, C. (2008): "La diferencia producida en una década. Reflexiones sobre la investigación "emancipadora” en discapacidad en Barton, L. (comp). Superar las barreras de la discapacidad. Madrid: Morata.

Casado, D. (coord.) (1998): "En busca de un sistema conceptual para la discapacidad” en Casado, D. y García, J., Discapacidad y comunicación social. $4^{a}$ edición Madrid: Real Patronato de prevención y Atención a Personas con Minusvalía.

De lorenzo, R., y Cayo, L. (directores) (2007): Tratado sobre discapacidad. Navarra :Thomson-Aranzadi.

Díaz, E. (2010): "Ciudadanía, identidad y exclusión social de las personas con discapacidad”. Política y Sociedad, 2010, Vol. 47, nº 1, pp. 115-135.

Fernández, A. (2006): "El Handikkappombudsman de Suecia” en VVAA. Un encuentro entre dos culturas. Un viaje a Suecia. Badajoz: Futuex.

Folger, J. P., y Jones, T. S. (coops.) (1997). Nuevas direcciones en mediación: investigación y perspectivas comunicacionales. Buenos Aires: Paidós.

Ganzenmüller, C. (2007): "Mecanismos de garantía de los derechos de las personas con discapacidad en el conjunto del ordenamiento jurídico” en De Lorenzo, R., y Cayo, L. (directores). Tratado sobre discapacidad. Navarra: Thomson-Aranzadi.

García, L. y Bolaños, I. (2006): La mediación familiar: una aproximación interdisciplinar.Gijón: Asociación de Mujeres Separadas y Divorciadas de Asturias.

Gerber, D. A. (2008): "Escuchar a las personas con discapacidad. El problema de la voz y la autoridad en el libro de Robert B. Edgerton The Cloak of Competence" en Barton, L. (comp) Superar las barreras de la discapacidad. Madrid: Morata.

Fernández, P. (2010): "La sociedad española en el siglo XXI. La construcción de un derecho subjetivo de ciudadanía” en Alemán, C., Alonso, J. Mª y Fernández, P. (coordinadores) Dependencia y Servicios Sociales. Navarra: Aranzadi.

Munuera Gómez, M. P. (2006): "Mediación en situaciones de dependencia: Conceptos claves y marco jurídico relevante" Revista Acciones e Investigaciones Sociales, extra, pp. 1-30.

(2012): "Nuevos espacios en mediación. Mediación en salud y dependencias” en Rondón, L. M. Bases para la Mediación. Valencia: Tirant Lo Blanch.

Munuera, M. P. y Rondón, L. M. (2010): “Mediación y Resolución de conflictos con personas en situación de dependencia” en Alemán, C. y otros, Dependencia y Servicios Sociales. Navarra: Aranzadi. 
Oliver, M. (1998): “¿Una sociología de la discapacidad o una sociología discapacitada?” en Barton , L. (comp.) (1998). Discapacidad y sociedad. Madrid: Morata.

Palacios, A. y Romañach, J. (2007): El modelo de la diversidad. La Bioética y los Derechos Humanos como herramientas para alcanzar la plena dignidad en la diversidad funcional. Valencia: Diversitas-AIES.

Peñas, E. y otros (2010): Los estudiantes cuentan. Madrid: Universidad sin barreras.

Puig de Bellacasa, R. (1998): "Concepciones, paradigmas y evolución de las mentalidades sobre la discapacidad” en Casado, D. y García, J. M. (1998) Discapacidad y comunicación social. $4^{\text {a }}$ edición. Madrid: Real Patronato de prevención y Atención a Personas con Minusvalía

Ripol-Millet, A. (2001): Familias...trabajo social...y mediación. Barcelona: Paidós. Six, J. F. (1997). Dinámica de la mediación. Barcelona: Paidós.

\section{Legislación}

Ley de Integración Social de los Minusválidos (LISMI), Ley 13/1982 de 7 de Abril, publicada en el BOE. núm. 103 de 30 de abril de 1982.

Ley de igualdad de oportunidades, no discriminación y accesibilidad universal de las personas con discapacidad, Ley 51/2003, de 2 de diciembre, publicada en el BOE núm. 289 de 3 de diciembre de 2003 (LIONDAU).

Real Decreto 1417/2006, de 1 de diciembre, por el que se establece el sistema arbitral para la resolución de quejas y reclamaciones en materia de igualdad de oportunidades, no discriminación y accesibilidad por razón de discapacidad

Convención Internacional sobre los Derechos de las Personas con Discapacidad, aprobada el 13 de diciembre de 2006.

Ley 39/2006, de 14 de diciembre, de Promoción de la Autonomía Personal y Atención a las personas en situación de dependencia, publicada el 15 de diciembre de 2006.

Ley 26/2011, de 1 de agosto, de adaptación normativa a la Convención Internacional sobre los Derechos de las Personas con Discapacidad. 